\title{
Diabetes Mellitus and Hypertension among Patients on Combination Antiretroviral Therapy in Civil Service Hospital, Nigeria
}

\author{
Shakirat I. Bello ${ }^{1}$, Felicia E. Williams ${ }^{1}$, Nusirat O. Bello ${ }^{1}$, Mathew A. Ajulo ${ }^{2}$, \\ Abdulrasheed A. Yusuf ${ }^{1}$ and Hafis G. Lawal ${ }^{1}$ \\ ${ }^{1}$ Department of Clinical Pharmacy and Pharmacy Practice, Faculty of Pharmaceutical Sciences \\ University of Ilorin, Ilorin, Nigeria \\ ${ }^{2}$ Department of Clinical Pharmacy and Pharmacy Practice, Faculty of Pharmacy, \\ University of Uyo, Uyo, Nigeria
}

(Received: March 4, 2020; Accepted: July 13, 2020; Published (web): July 25, 2020)

\begin{abstract}
The utilization of combination antiretroviral therapy (cART) in the management of Human Immunodeficiency Virus (HIV) infection could lead to diabetes mellitus and hypertension. Therefore, this study was conducted to determine the incidence and risks for diabetes mellitus and hypertension amongst HIV-infected patients on cART at ART Clinic of Civil Service Hospital, Ilorin, Nigeria. Crosssectional research was conducted among 262 consented HIV-infected patients on cART from April to July 2018. Random blood sugar and blood pressure of the patients were measured with glucometer and sphygmomanometer, respectively. The subjects were administered with standardized sociodemographics, treatment, and clinical variable forms. Descriptive and inferential statistics were used, and ethical approval was obtained. The patients had a mean age of $44.32 \pm 11.60$ years and had received cART for a median duration of $6.01 \pm 2.16$ years. There was a high incidence $(18.3 \%)$ of hypertension and diabetes mellitus diseases among the patients on cART. The majority of $32(66.67 \%)$ of the patients were on Efavirenz + Lamivudine + Tenofovir combination therapy. The risk factors for the comorbidity were gender (OR 1.113; 95\% CI 0.014-0.938, p < 0.043), duration on HIV infection (OR 1.084; 95\% CI $0.860-1.366, \mathrm{p}<0.049$ ), duration on cART (OR 1.928; 95\% CI 0.861-1.679, p < 0.048) and types of cART (OR 1.042; 95\% CI 1.000-1.085, p < 0.047). The high incidence of the comorbid conditions in HIV-infected patients on cART affirms the necessity to integrate screening for these two concomitant diseases in the HIV program as part of a healthcare support strategy.
\end{abstract}

Key words: Diabetes mellitus, hypertension, Human Immunodeficiency Virus (HIV) patients, Combination antiretroviral therapy, Nigeria

\section{Introduction}

According to the latest United Nations Acquired Immunodeficiency Syndrome (AIDS) and Human Immunodeficiency Virus (HIV) data, there are 36.7 million people globally living with HIV infection and 19.5 million receiving combination anti-retroviral therapy (cART) (UNAIDS, 2018). Advances in infectious disease detection and cART have increased life expectancy in people living with HIV-infection and AIDS, with substantial diminution in the frequency of AIDS-related complications and deaths (Fazekas-Lavu et al., 2018). As HIV-positive populations age in this era of cART availability for HIV-patients, there is a need to understand the health implications of the growing burden of cardiovascular and metabolic diseases of the patients (Werfali et al., 2016; Kaze et al., 2017). The information is pertinent for the resource-limited health systems in subSaharan Africa that face the epidemics and a growing prevalence of diabetes and hypertension among the adults (Manne-Goehler et al., 2019).

Correspondence to: Shakirat. I. Bello; Tel.+2348035675609; E-mail:sibello10@yahoo.com

DOI: https://doi.org/10.3329/bpj.v23i1.48332 
A better understanding of the connection between HIV and cardiovascular-metabolic conditions has the promise of improving human health (Reich et al., 2015; Palma et al., 2016). A study conducted in Nigeria revealed an increase in the prevalence of hypertension after 2 years of initiation on cART (Denue et al., 2012). In Ethiopia (Ataro et al., 2018) and Uganda (Kazooba et al., 2017) high prevalence of diabetes mellitus and hypertension in patients on cART were observed. In Senegal, the prevalence of hypertension and diabetes mellitus increased was observed to have increased from $11 \%$ to $22 \%$ (Benzekri et al., 2019).

The risk of diabetes mellitus is increased among HIV infected patients and is associated with cumulative exposure to cART (Ryscavage et al., 2017, Xu et al., 2017). Studies have reported different risk factors associated with hypertension and diabetes mellitus diseases among patients with HIV infection. Most of the risk factors for these diseases include; age, sex, ethnicity, family history, physical activity, smoking, alcohol use, CD4 count, duration, and type of cART (Isa, 2015). These diseases have a significant undesirable impact on the treatment of patients infected with HIV and their quality of life. The resulting metabolic imbalances due to the diabetes mellitus and hypertension could affect the long-term prognosis of HIV patients (Fazekas-Lavu et al., 2018; Haacker et al., 2019). Furthermore, the coexistence of diabetes mellitus and hypertension in HIV-infected individuals may complicate the management of HIV infection and increase the risk of morbidity and mortality of these individuals (Todowede et al., 2019).

On this background, this study was conducted to determine the incidence and risk for diabetes mellitus and hypertension amongst HIV-infected patients on cART.

\section{Materials and Methods}

Study area: Civil Service Hospital (CSH) is located in Ilorin West Local Government Area, Kwara State, Nigeria. It is a secondary health care facility run by Kwara State Ministry of Health. CSH is a 32-bed hospital and provides in-patient and outpatient medical services to people in Kwara State and neighboring states. The facility was initially established to provide healthcare services for the civil servants but the scope of service has been extended to the general public. The facility has pharmacists, physicians, nurses, and other healthcare providers (Nigeria Directory, 2019).

Ethical consideration and approval: The study was conducted in the $\mathrm{CSH}$ after receiving ethical approval from the Ethics and Research Committee of Kwara State Ministry of Health, Ilorin with reference number MOH/KS/EU/777/214 and dated 18/12/2017. The written and oral consents of the patients were sought before enrolment, while confidentiality and privacy were maintained according to ethical guidelines.

Study design: A hospital-based cross-sectional study conducted from April to July, 2018 which involved HIV infected patients on cART. Random blood sugar and blood pressure were measured using glucometer and sphygmomanometer respectively. The body mass index (BMI) was obtained by measuring their heights and weights using a weighing balance that contained a height scale. The inclusion criteria were male and female outpatients diagnosed to be HIV-infected, patients aged 20 years and above, those on cART for at least thirty-six months, patients who refilled prescriptions at the Pharmacy Unit of the hospital, and those consented to participate in the study. Patients on hospital admissions, pregnant women, those with a documented history of hypertension, diabetes mellitus, renal disease, and dyslipidaemia before the commencement of cART, those on medications that could affect blood pressure and blood sugar levels and patients who declined consent were excluded.

Patients and sample size: The sample size was determined using the statistical formula described by Abazie et al. (2014).

$\mathrm{n}=\mathrm{Z}^{2} \mathrm{pq} / \mathrm{d}^{2}$

where: $\mathrm{n}=$ minimum sample size for a statistically significant survey, $\mathrm{Z}=$ standard normal deviate set at 1.96 (approx. 2.0), $q=1-\mathrm{p}, \mathrm{q}=$ complement of $\mathrm{p}$ 
$\mathrm{n}=384$

As at 2018, the number of HIV infected patients on cART at Civil Service Hospital was 825, the minimum sample size for a population less than 10,000 was determined thus:

$$
\mathrm{nf}=\mathrm{n} /(1+\mathrm{n} / \mathrm{N})
$$

Where, $\mathrm{nf}=$ Desired sample size, $\mathrm{n}=$ sample size for a population greater than 10,000 (384) $\mathrm{N}=$ estimate of the study population (825)

$$
\mathrm{nf}=262
$$

Therefore, the number of patients enrolled in the study was 262.

Patient selection: Patients who met the inclusion criteria were enrolled consecutively until the required number of patients was achieved.

Data collection instruments: The patients' demographic form was used in capturing patients' age, gender, education, marital and occupational statuses. The treatment variable form was used to elicit information on the duration and types of cART. The patients' clinical data on the World Health Organization (WHO) HIV clinical staging, weight, height, blood pressure, random blood sugar, years of $\mathrm{HIV}$ diagnosis, and $\mathrm{CD}_{4}$ count level were documented using standardized forms. Weight was evaluated with weighing balance placed on a hard flat surface while height was assessed when the patient faced directly ahead. The blood pressure was measured by allowing the patient to relax for fifteen minutes, and then the blood pressure cuff was placed on the patients' arm using an aneroid sphygmomanometer (Agary Pharmaceutical Limited by Changzhou Kanger Medical Equipment Co. Limited, China). The reading was steadily obtained from the left arm four times at ten minutes interval. The mean obtained from the four readings was utilized in the statistical analysis. BMI was computed as a ratio between weight $(\mathrm{kg})$ and the square of height $(\mathrm{m})$. To determine the random blood sugar level, the patients' fingers were pricked and a small amount of blood was drawn onto a test strip to obtain the glucose readings with the use of blood glucometer (Infopia Company Limited, Gyeonggi Province, South Korea).
Definitions of term: Patients were diagnosed to have diabetes mellitus if they had a random blood sugar of $\geq 200 \mathrm{mg} / \mathrm{dL}$ (ADA, 2015). Overweight and obesity were defined as a BMI $\geq 25$ and $30 \mathrm{~kg} / \mathrm{m}^{2}$, respectively. Underweight was defined as $\mathrm{BMI} \leq 18.5$ $\mathrm{kg} / \mathrm{m}^{2}$, while normal as $18.5-24.99 \mathrm{~kg} / \mathrm{m}^{2}$ (Sabir et al., 2017). Hypertension was defined as systolic blood pressure $\geq 140 \mathrm{mmHg}$ and/or diastolic blood pressure $\geq 90 \mathrm{mmHg}$ (Ogbera and Ekpebegh, 2014).

Data analysis: The data collected for the study were analyzed using the PROC MIXED procedure in SAS (SAS version 9.1.3, SAS Institute, 2012). Means and proportions in descriptive statistics were used to calculate for the continuous and discrete variables, respectively. Inferential statistics used for the analysis were the chi-square test, for the test of association for categorical data. The logistic regression analysis model was also used to test for the association between diabetes mellitus, hypertension, and risk factors. The level of statistical significance was set at $\mathrm{p}<0.05$.

\section{Results and Discussion}

Socio-demographic features of the patients: Among the 262 patients studied 52 (19.8\%) were males and $210(80.2 \%)$ were females, with a male to female ratio of 1:4. The age ranged from 20 to 80 years, with a mean age of $44.32 \pm 11.60$ years. The majority $192(73.3 \%)$ of the subjects were married. One hundred and forty-two (54.2\%) were literates (at least they completed senior secondary school) while the majority were unemployed 154 (58.8\%) (Table $1)$.

Incidence of diabetes mellitus and hypertension: Two hundred and fourteen $(81.7 \%)$ of the patients on cART had neither diabetes mellitus nor hypertension while $48(18.3 \%)$ had these non-communicable diseases (Table 2). The incidence rate of diabetes mellitus and hypertension among studied patients was $18.3 \%$.

Demographic and treatment variables of patients on cART: There were statistically significant differences between males and females with regard to diabetes mellitus and hypertension at $\mathrm{p}<0.033$ 
(Table 3). Out of forty-eight patients with the comorbidity of the two diseases, forty-six were females. Most of the patients with comorbidities 32 $(66.7 \%)$ were within the age range of 30 to 49 years. More than half $32(66.67 \%)$ of the patients were on Tenofovir + Lamivudine + Efavirenz followed by

Table 1. Socio-demographic characteristics of the patients. those on Zidovudine + Lamivudine + Nevirapine 14 $(29.17 \%)$ and very few $2(1.4 \%)$ were on Tenofovir + Lamivudine + Lopinavir/Ritonavir. Twenty-two $(45.8 \%)$ of the patients were on cART for over six years with median duration of $6.01 \pm 2.16$ years.

\begin{tabular}{|c|c|c|}
\hline Variables & Frequency & Percentage \\
\hline \multicolumn{3}{|l|}{ Age (years) } \\
\hline $20-29$ & 70 & 26.70 \\
\hline $30-39$ & 62 & 23.70 \\
\hline $40-49$ & 86 & 32.80 \\
\hline $50-59$ & 34 & 13.00 \\
\hline $60-80$ & 10 & 3.80 \\
\hline Mean age (years) $\pm S D$ & $44.32 \pm 11.60$ & \\
\hline \multicolumn{3}{|l|}{ Gender } \\
\hline Male & 52 & 19.80 \\
\hline Female & 210 & 80.20 \\
\hline \multicolumn{3}{|l|}{ Marital status } \\
\hline Single & 54 & 20.60 \\
\hline Married & 192 & 73.30 \\
\hline Separated & 2 & 0.80 \\
\hline Divorced & 4 & 1.50 \\
\hline Widowed & 10 & 3.80 \\
\hline \multicolumn{3}{|l|}{ Educational status } \\
\hline No formal education & 40 & 15.30 \\
\hline Primary education completed & 44 & 16.80 \\
\hline Junior Secondary education completed & 32 & 12.20 \\
\hline Senior Secondary education completed & 66 & 25.20 \\
\hline Tertiary education completed & 76 & 29.00 \\
\hline Arabic & 4 & 1.50 \\
\hline \multicolumn{3}{|l|}{ Occupation } \\
\hline Employed & 72 & 27.50 \\
\hline Trading & 20 & 7.60 \\
\hline Unemployed & 154 & 58.80 \\
\hline Students & 12 & 4.60 \\
\hline Retired civil servants & 4 & 1.50 \\
\hline
\end{tabular}

Source: Field survey 2018. SD=Standard deviation

In Table 4, fifty percent of the patients (24) with the comorbidities were underweight, few $2(4.2 \%)$ had class 1 obesity with $6(12.5 \%)$ being overweight.
The patients were found in all the stages of HIV infection. However, those on stages 1 and 2 were slightly higher $132(50.4 \%)$ than other stages (3 and 
4). One half (24) of the comorbid patients were in the advanced stage of the infection and $32(66.7 \%)$ were diagnosed with HIV infection between 4 and 9 years.
The majority of the patients $28(58.3 \%)$ had a $\mathrm{CD}_{4}$ count of greater than 500 cells $/ \mu \mathrm{L}$.

Table 2. Incidence of diabetes mellitus and hypertension among patients on cART.

\begin{tabular}{lcc}
\hline Assessment of random blood sugar and systemic blood pressure & $\begin{array}{c}\text { No. of HIV } \\
\text { patients }\end{array}$ & $\begin{array}{c}\text { Percentage } \\
(\%)\end{array}$ \\
\hline Patients with diabetes mellitus and hypertension & 48 & 18.3 \\
Patients without diabetes mellitus and hypertension & 214 & 81.7 \\
Incidence of diabetes mellitus and hypertension among the studied patients & $\mathbf{1 8 . 3}$ \\
\hline
\end{tabular}

Table 3. Demographic and treatment variables of patients on cART.

\begin{tabular}{|c|c|c|c|c|}
\hline Variables & $\begin{array}{l}\text { Patients with diabetes } \\
\text { mellitus and hypertension } \\
\quad(\mathrm{n}=48), \mathrm{n}(\%)\end{array}$ & $\begin{array}{l}\text { Patients without diabetes } \\
\text { mellitus and hypertension } \\
\qquad(\mathrm{n}=214) \mathrm{n}(\%)\end{array}$ & $\chi^{2}$ & $\mathrm{P}$ \\
\hline \multicolumn{5}{|l|}{ Gender } \\
\hline Male & $2(4.2)$ & $50(23.4)$ & 4.542 & $0.033^{*}$ \\
\hline Female & $46(95.8)$ & $164(76.6)$ & & \\
\hline \multicolumn{5}{|l|}{ Age (years) } \\
\hline $20-29$ & $6(12.5)$ & $64(26.2)$ & 2.127 & 0.712 \\
\hline $30-39$ & $14(29.2)$ & $48(31.8)$ & & \\
\hline $40-49$ & $18(37.5)$ & $68(26.2)$ & & \\
\hline $50-59$ & $8(16.7)$ & $26(12.1)$ & & \\
\hline$>60$ & $2(4.1)$ & $8(3.7)$ & & \\
\hline \multicolumn{5}{|l|}{ Duration on cART (Years) } \\
\hline$<3$ & $8(16.7)$ & $92(43.0)$ & 1.591 & 0.451 \\
\hline $3-6$ & $18(37.5)$ & $60(28.0)$ & & \\
\hline$>6$ & $22(45.8)$ & $62(29.0)$ & & \\
\hline Median Duration on cART & & $6.01 \pm 2.16($ Years $) \pm$ SD & & \\
\hline \multicolumn{5}{|l|}{ Types of cART } \\
\hline TLE & $32(66.7)$ & $152(71.0)$ & 0.407 & 0.339 \\
\hline ZLN & $14(29.2)$ & $40(18.7)$ & & \\
\hline $\mathrm{ZLL} / \mathrm{r}$ & $0(0.0)$ & $12(5.6)$ & & \\
\hline $\mathrm{TLL} / \mathrm{r}$ & $2(4.1)$ & $10(4.7)$ & & \\
\hline
\end{tabular}

$*$ Significant at $\mathrm{p} \leq 0.05$. TLE $=$ Tenofovir + Lamivudine + Emtricitabine $; \mathrm{ZLN}=$ Zidovudine + Lamivudine + Nevirapine ZLL/r = Zidovudine + Lamivudine + Lopinavir/Ritonavir; TLL/ r = Tenofovir + Lamivudine + Lopinavir/Ritonavir.

The odds of diabetes mellitus and hypertension among HIV patients on cART significantly increased by $1.9 \%$ in females (OR $1.113,95 \%$ CI $0.014-0.938$, $\mathrm{p}<0.043$ ) (Table 5). The non-communicable diseases decreased, though not significant by $1 \%$ in years of age (OR $0.99,95 \%$ CI $0.949-1.032, \mathrm{p}<$
0.628 ) but increased significantly by $8.4 \%$ as HIV duration increases (OR 1.084, 95\% CI 0.860-1.366, p $<0.049)$ and increased by $4.8 \%$ insignificantly as BMI increases (OR 1.048, 95\% CI 0.960-1.212, p < 0.529). Also, the odds for diabetes mellitus and hypertension among patients who have spent six 
years on cART increases by $1.9 \%$ (OR 1.928, 95\% CI 0.861-1.679) at a statistically significant value of $\mathrm{p}<0.048$. The types of cART (OR 1.042; 95\% CI $1.000-1.085, \mathrm{p}<0.047$ ) were significantly associated with diabetes mellitus and hypertension. However, the logistic regression analysis of the dependent variable (risk factors for diabetes mellitus and hypertension) and the independent variables (sociodemographic, clinical, and treatment variables) among these patients were associated with the gender, duration on HIV infection, duration and types of cART.

Table 4. Clinical distribution of patients on cART with diabetes mellitus and hypertension.

\begin{tabular}{|c|c|c|c|c|}
\hline Variables & $\begin{array}{l}\text { Patients with diabetes } \\
\text { mellitus and hypertension } \\
(\mathrm{n}=48), \mathrm{n}(\%)\end{array}$ & $\begin{array}{l}\text { Patients without diabetes } \\
\text { mellitus and hypertension } \\
(\mathrm{n}=214) \mathrm{n}(\%)\end{array}$ & $\chi^{2}$ & $P$ \\
\hline \multicolumn{5}{|l|}{ Body Mass Index } \\
\hline Underweight $(<18.5)$ & $24(50.0)$ & $106(49.5)$ & 1.127 & 0.288 \\
\hline Normal (18.5 - 24.9) & $16(33.3)$ & $94(43.9)$ & & \\
\hline Overweight $(25.0-29.9)$ & $6(12.5)$ & $12(5.7)$ & & \\
\hline Class I obesity $(30.0$ - 34.9) & $2(4.2)$ & $2(0.9)$ & & \\
\hline Class II obesity $(35.0$ - 39.9) & - & - & & \\
\hline Class III obesity ( $\geq 40.0$ ) & - & - & & \\
\hline \multicolumn{5}{|l|}{ WHO HIV Stage } \\
\hline Mild- moderate $(1 \& 2)$ & $24(50.0)$ & $108(50.5)$ & $0.002 *$ & 0.967 \\
\hline Severe-advance $(3 \& 4)$ & $24(50.0)$ & $106(49.5)$ & & \\
\hline \multicolumn{5}{|l|}{ Years of HIV Diagnosis } \\
\hline$<4$ & $16(33.3)$ & 96 (44.9) & 1.397 & 0.497 \\
\hline $4-6$ & $16(33.3)$ & $50(23.4)$ & & \\
\hline $7-9$ & $16(33.4)$ & $68(31.8)$ & & \\
\hline \multicolumn{5}{|l|}{$\mathrm{CD}_{4}$ Cells Count (cells/ $\left.\mu \mathrm{l}\right)$} \\
\hline$<250$ & $2(4.2)$ & $30(14.0)$ & 0.202 & 0.653 \\
\hline $250-500$ & $18(37.5)$ & $70(32.7)$ & & \\
\hline$>500$ & $28(58.3)$ & $114(53.3)$ & & \\
\hline
\end{tabular}

*Significant at $\mathrm{p} \leq 0.05$.

Table 5. Logistic regression analysis for risk factors for diabetes mellitus and hypertension among patients on cART.

\begin{tabular}{lcccc}
\hline Risk factors & P-value & Odds ratio & \multicolumn{2}{c}{$(95 \% \mathrm{Cl})$} \\
\cline { 4 - 5 } & & & Lower & Upper \\
\hline Gender (female) & $0.043^{*}$ & 1.113 & 0.014 & 0.938 \\
Age & 0.628 & 0.990 & 0.949 & 1.032 \\
Duration on HIV (years) & $0.049^{*}$ & 1.084 & 0.860 & 1.366 \\
BMI & 0.529 & 1.048 & 0.906 & 1.212 \\
Duration on cART & $0.048^{*}$ & 1.928 & 0.861 & 1.679 \\
HIV staging (mild) & 0.452 & 0.678 & 0.247 & 1.863 \\
CD4 & 0.996 & 1.000 & 0.998 & 1.002 \\
Types of cART & $0.047^{*}$ & 1.042 & 1.000 & 1.085 \\
\hline
\end{tabular}

*Significant at $\mathrm{p} \leq 0.05$. BMI=Body mass index. 
Understanding the risks of hypertension and diabetes mellitus in HIV-infected patients will be important to public health to prevent metabolic and cardiovascular complications, and premature death among patients receiving cART (Xu et al., 2017). The incidence of hypertension and diabetes mellitus was found to be much greater in HIV infected females than in males. This might be attributed to a larger proportion of the HIV female patients than males. Women were 2 to 4 times more vulnerable to HIV infection than men during unprotected sexual intercourse because of larger surface areas exposed to contact (Dellar et al., 2015). Contrarily, Samaras (2012) and Reid et al. (2012) observed that HIVinfected women on cART have a lower risk of developing diabetes and hypertension as compared with men. Also, most of the patients with the comorbidities were between the age ranges of 40-49 years although age is not a risk factor for noncommunicable diseases in the present study. These findings were inconsistent with that of Hasse et al. (2011) and Ameesh et al. (2017) where age is considered as a risk factor, and older HIV infected people (above 65 years) were four times vulnerable to diabetes mellitus and hypertension as compared with those of age 50 years. In this study, most of the patients with comorbidities were underweight as BMI is not significantly linked to these conditions. This was contrary to Sabir et al. (2017) who reported a high incidence of DM and hypertension among obese and overweight patients. The rationale was that obesity is associated with fat deposition, particularly in the liver which leads to a decrease in insulin sensitivity. Factors such as female gender, duration of HIV infection, types of cART and duration on cART were significantly associated with the risks of diabetes mellitus and hypertension, whereas body mass index, age, CD4 count, and HIV staging were not. Hernandez-Romieu et al. (2017) supported this study as the duration of HIV infection was responsible for the non-communicable diseases among their patients. However, these observations were not in agreement with the results of Samad et al. (2017) who reported age, male sex, obesity, family history, and hepatitis $\mathrm{C}$ co-infection as risks for development of the non-communicable diseases among patients receiving cART. Furthermore, Ataro et al. (2018) reported that increased blood triglyceride, high blood pressure, high baseline body mass index, raised waist-hip ratio, raised blood glucose, increased total cholesterol, CD4 count $<500$ cell/ $\mu \mathrm{L}$, drinking alcohol and longer duration of cART were significantly associated with diabetes mellitus and hypertension. Another study by Isa (2015) showed that regimens containing nonnucleoside reverse transcriptase inhibitors and/or protease inhibitors were associated with hypertension and diabetes among HIV infected patients in Sub Saharan African. The current study observed that all the classes of cART used by the patients increased their tendencies to develop diabetes mellitus and hypertension except Tenofovir + Lamivudine + Lopinavir/Ritonavir combination therapy. These phenomena may explain the association of long-term exposure to cART with the development of diabetes mellitus. The cART could directly affect mitochondrial function which has implications in the pathogenesis of insulin resistance and glucose abnormalities among HIV-infected patients. These results differed from the findings of Isa (2015) that all cART regimens were independently associated with diabetes. This study concurred with Mesenga et al. (2019) that higher $\mathrm{CD}_{4}$ cell counts were associated with hypertension in ART-treated participants. The rationale might be due to chronic immune activation. HIV viral protein and ART interact with components of the immune system to synergistically induce the release of cytokines causing kidney damage, promote vascular dysfunction, alterations in sympathetic nervous outflow, retention of sodium, and water, leading to hypertension (Rodriguez-Iturbe et al., 2017).

Studies on diabetes mellitus and hypertension among HIV infected patients on cART reported a wide range of prevalence. The incidence rate of diabetes and hypertension in this study was (18.32 $\%)$. This finding is lower than a study conducted by Sachithananthan et al. (2013) among HIV-infected 
patients on cART in Ethiopia (15.9\%). However, the finding is comparable to the study done by Julius $e t$ al. (2011) in South Africa (19.1\%) and Hejazi et al. (2013) in Malaysia (19.7\%). Furthermore, the outcomes of the research studies of Arruda et al. (2010) in Brazil (25.6\%), Mateen et al. (2013) in Uganda (27.9\%), Diouf et al. (2012) in Senegal (28.1\%), Palacious et al. (2006) in Spain (26.0\%) and Coloma et al. (2008) in the United States of America $(25.0 \%)$ were much higher than the findings of this study. The differences observed could be due to variation in types of cART, duration of HIV infection itself, stage of HIV infection, sex, lifestyle, and age difference of the study participants, study design, methods used, variations in the cutoff values for hypertension and diabetes mellitus.

\section{Conclusion}

The study identified a high incidence of diabetes mellitus and hypertension among the patients on cART. The risks of these co-morbid diseases were gender, duration on HIV infection, duration, and types of cART.

\section{Recommendation}

There is a need to integrate screening for diabetes mellitus and hypertension in HIV programme as part of the healthcare support strategy for early detection and prevention of cardiovascular and metabolic diseases in HIV infected patients on cART.

\section{Acknowledgments}

The authors greatly appreciate the management of Kwara State Ministry for granting ethical approval to conduct this research. Our special thanks go to the staff of Civil Service Hospital for their unrelenting support during data collection. We are grateful to the patients for their willingness to partake in this study.

\section{References}

Abazie, H.O. and Abimbola, O. 2014. Perceived health believes of breast cancer and knowledge of its early detection measures among rural women in Umuduru Mbano, Imo State. J. Pub. Hlth. Epid. 6, 148-157.
Ameesh, M. and Murugan, S. 2017. Prevalence and its risk factors of diabetic patients in urban area of Palakkad: an observational study. Int. J. Commun. Med. Pub. Health. 4, 3721-3726.

American Diabetes Association (ADA) 2015. Classification and diagnosis of diabetes. Sec. 2. In Standards of Medical Care in Diabetes. Diab. Care. 38, S8-S16

Arruda J., E.R., Lacerda, H.R., Moura, L.C., Albuquerque Mde, F., Miranda F., B., Diniz, G.T., Albuquerque, V.M., Amaral, J.C., Ximenes, R.A. and Monteiro, V.S. 2010. Risk factors related to hypertension among patients in a cohort living with HIV/AIDS. Braz. J. Infect. Dis.14, 281-287.

Ataro, Z., Ashenafi, W., Fayera, J. and Abdosh, T. 2018. Magnitude and associated factors of diabetes mellitus and hypertension among adult HIV-positive individuals receiving highly active antiretroviral therapy at Jugal Hospital, Harar, Ethiopia. HIV/AIDS - Res. Palli. Care. 10,181-192.

Benzekri, N.A., Seydi, M. Doye, I. N., Toure, M., Sy, M.P., Kiviat, N.B., Sow, P.S., Gottlieb, G.S. and Hawes, S.E. 2019. Correction: Increasing prevalence of hypertension among HIV-positive and negative adults in Senegal, West Africa, 1994-2015. Plos One.14, doi.org/10.1371/journal.pone.0212250 View correction.

Coloma, A.C., Alvarez, M.A., Roca-Cusachs, A.C., Domingo, P.P. and Puig, M.C. 2008. Prevalence of arterial hypertension and lipid profile in HIV patients. Med. Clin. 131, 681-684.

Dellar, R. C, Dlamini, S. and Karim, A.Q. 2015. Adolescent girls and young women: key populations for HIV epidemic control. J. Int. AIDS Soc. 18, doi: 10.7448/IAS.18.2.19408.

Denue, A., Muazu, J., Gashau, W., Nkami, D. and Ajayi, N.A. 2012. Effects of highly active antiretroviral therapy (HAART) on blood pressure changes and its associated factors in HAART naive HIV-infected patients in north eastern Nigeria. Arch. Appl. Sci. Res. 4, 1447-1452.

Diouf, A., Cournil, A., Ba-Fall, K., Ngom-Guèye, N.F., Eymard-Duvernayn, S., Ndiaye, I., Batista, G., Mandoumbé Guèye, P., Samba, B.P., Taverne, B., Delaporte, E. and Sow, P.S. 2012. Diabetes and hypertension among patients receiving antiretroviral treatment since 1998 in Senegal: prevalence and associated factors. Int. Schol. Res. Notices on AIDS. 2012, 1-8. 
Fazekas-Lavu, M., Tonks, K.T.T. and Samaras, K. 2018. Benchmarks of diabetes care in men living with treated HIV-infection: A tertiary center experience. front. Endocrinol.9, doi: 10.3389/fendo.2018.00634.

Haacker, M., Bärnighausen, T. and Atun, R. 2019. HIV and the growing health burden from noncommunicable diseases in Botswana: modeling study. $J$ Glob Health.9, doi: 10.7189/Jogh.09.010428.

Hasse, B., Ledergerber, B., Furrer, H., Battegay, M, Hirschel, B., Cavassini, M., Bertisch, B., Bernasconi, E. and Weber, R. 2011.Swiss HIV cohort study. Morbidity and aging in HIV-infected persons: the Swiss HIV cohort study. Clin. Infect. Dis. 53, 11301139.

Hejazi, N., Rajikan, R., Kwok Choong, C.L. and Sahar, S. 2013. Metabolic abnormalities in adult HIV infected population on antiretroviral medication in Malaysia: a cross-sectional survey. BMC Pub. Health. 13,758. doi: 10.1186/1471-2458-13-758.

Hernandez-Romieu, A. C., Garg Shikha, S., Rosenberg, E., Thompson-Paul, A. M. and Skarbinski, J. 2017. Is diabetes prevalence higher among HIV-infected individuals compared with the general population? Evidence from MMP and NHANES 2009-2010. BMJ Open Diabetes Res. Care. 5, doi: 10.1136/bmjdrc2016-000304.

Isa, S.E. 2015. Cardiovascular disease in HIV-infected patients: a focus on diabetes mellitus and hypertension? Afr. J. Diab. Med. 23, 1-7.

Julius, H., Basu, D., Ricci, E., Wing, J., Basu, J.K., Pocaterra, D. and Bonfanti. P. 2011. The burden of metabolic diseases amongst HIV positive patients on HAART attending the Johannesburg Hospital. Curr. HIV Res. 9, 247-252.

Kaze, A.D., Schutte, A.E., Erqou, S., Kengne, A.P. and Echouffo-Tcheugui, J.B. 2017. Prevalence of hypertension in older people in Africa: a systematic review and meta-analysis. J. Hypertens. 35, 1345-352.

Kazooba, P., Kasamba, I, Mayanja, B.N., Lutaakome, J., Namakoola, I., Salome, T., Kaleebu, P. and Munderi, P. 2017. Cardiometabolic risk among hiv-positive Ugandan adults: prevalence, predictors and effect of long-term antiretroviral therapy. The Pan. Afri. Med. J. 27, doi:10.11604/pamj.2017.27.40.9840.

Manne-Goehler, J., Siedner, M.J., Montana, L., Harling, G., Geldsetzer, P., Goehler, A., Wade, A., Gaziano, T, Kahn, K., Davies, J.I., Tollman, S. and Bärnighausen, T.W. 2019. Hypertension and diabetes control along the HIV care cascade in rural South Africa. J. Intern. AIDS Soc. 22,10.1002/jia2.25213.
Mateen, F.J., Kanters, S. and Kalyesubula, R. 2013. Hypertension prevalence and Framingham risk score stratification in a large HIV-positive cohort in Uganda. J. Hypertens. 31, 1372-1378.

Masenga, S.K., Hamooya, B.M., Nzala, S., Kwenda, G., Heimburger, D.C., Mutale, W., Munsaka, S.M., Koethe, J.R. and Kirabo, A. 2019. Patho-immune mechanisms of hypertension in hiv: a systematic and thematic review. Curr Hypertens Rep. 21, doi: 10.1007/s11906-019-0956-5.

Nigeria Directory - Civil Service Hospital Ilorin 2019. Available online at: https://www.directory.org.ng/ directory_civil_service_hospital_ilorin. Cited on 5/9/2019.

Ogbera, A.O. and Ekpebegh, C. 2014. Diabetes mellitus in Nigeria: the past, present and future. World J. Diab. 5, 905-911.

Palacios, R., Santos, J., García, A., Castells, E., González, M., Ruiz, J. and Márquez, M. 2006. Impact of highly active antiretroviral therapy on blood pressure in HIVinfected patients. A prospective study in a cohort of naive patients. HIV Med. 7, 10-15.

Palma, A.M., Rabkin, M., Nuwagaba-Biribonwoha, H., Bongomin, P., Lukhele, N., Dlamini, X, Kidane, A. and El-Sadr,W. M. 2016. Can the success of HIV scale-up advance the global chronic NCD agenda? Glob. Heart. 11, 403-408.

Reich, M.R., Harris, J., Ikegami, N., Maeda, A., Takemi, K. and Evans, T.G. 2015. Moving towards universal health coverage: lessons from 11 country studies. Lancet. 387, 811-816.

Reid, M.J., Tsima, B. and Kirk, B. 2012. HIV and diabetes in Africa. Afr. J. Diab. Med. 20, 1-5.

Rodriguez-Iturbe, B., Pons, H. and Johnson, R.J. 2017. Role of the immune system in hypertension. Physiol. Rev. 97, 1127-1164.

Ryscavage, P., Still, W., Nyemba, V. and Stafford, K. 2017. Prevalence of systemic hypertension among HIV-infected and HIV-uninfected young adults. Open Forum Infect Dis. 4, doi: 10.1093/ofid/ofx 162.138.

Sabir, A.A., Balarabe, S., Sani, A.A., Isezuo, S.A., Bello, K.S. and Jimoh, A.O. 2017. Prevalence of diabetes mellitus and its risk factors among the suburban population of Northwest Nigeria. Sahel Med. J. 20, 168-172.

Sachithananthan, V., Loha, E. and Gose, M. 2013. Prevalence of diabetes mellitus, hypertension and lipodystrophy in haart receiving hiv patients in Southern Ethiopia. Int. STD Res. Rev. 1, 1-11. 
Samad, F., Marianne, H., Cathy, M.P., Ye, M., Chia, J., Chacko, S., Bondy, G.P., Lima, V.D., Montaner, J.S.G. and Guillemi, S.A. 2017. Incidence of diabetes mellitus and factors associated with its development in HIV-positive patients over the age of 50. BMJ Open Diab. Res. Care. 5, doi: 10.1136/bmjdrc-2017000457.

Samaras, K. 2012. The burden of diabetes and hyperlipidemia in treated HIV infection and approaches for cardiometabolic care. Curr. HIV/AIDS Rep. 9, 206-217.

SAS, 2012. The Statistical Application Software (SAS) Statistics System for Windows Release Version 9.2. SAS Institute, Inc. Cary, NC, USA.

Todowede, O.O., Mianda, S.Z. and Sartorius, B. 2019. Prevalence of metabolic syndrome among HIVpositive and HIV-negative populations in sub-Saharan Africa- a systematic review and meta-analysis. Syst. Rev. 8, doi.org/10.1186/s13643-018-0927-y.
UNAIDS (2018). Global AIDS Update: Miles to goclosing gaps, breaking barriers, righting injustices; AIDSinfo website; available at: http://aidsinfo. unaids.org/. UNAIDS. Core Epidem. Slides. Accessed 19 April 2019.

Werfalli, M., Engel, M.E., Musekiwa, A., Kengne, A.P. and Levitt, N.S. 2016. The prevalence of type 2 diabetes among older people in Africa: a systematic review. Lancet Diab. Endocrinol.4, 72-84.

$\mathrm{Xu}$, Y., Chen, X. and Wang, K. 2017. Global prevalence of hypertension among people living with HIV: a systematic review and meta-analysis. J. Am. Soc. Hypertens. 11, 530-540. 